\author{
Revista Facultad 2021 \\ de Ciencias Básicas Vol. 17(1) \\ enero-junio - ISSN: 1900-4699 - e-ISSN: 2500-5316 - pp. 27-40
}

DOI: https://doi.org/10.18359/rfcb.5433

(C) $(1) \Theta$

\title{
Evaluación de Canavalia ensiformis y Vigna radiata como abonos verdes, sobre la dinámica microbiana del suelo de la finca El Plan de Burras, en el municipio de El Espino, Boyacá, Colombia*
}

\author{
Paula Andrea Pérez Caicedo ${ }^{a}$ Liliana Figueroa del Castillo ${ }^{b}$
}

\begin{abstract}
Resumen: la capacidad de las leguminosas como abonos verdes es reconocida y sigue siendo objeto de numerosos estudios. Por esta razón, el primer semestre de 2017 se evaluó el efecto de Canavalia ensiformis y Vigna radiata como abonos verdes, sobre la dinámica microbiana del suelo, sin historial de uso por siete años, de la finca El Plan de Burras, en El Espino, Boyacá, Colombia. Se evaluó el estado actual a través de los parámetros fisicoquímicos pH (6,2), capacidad intercambio catiónico (21,97 mEq/100 g), materia orgánica (3,06 \%), carbono total $(1,77 \%)$ y nitrógeno total $(0,15 \%)$. Los suelos fueron sometidos a tres tratamientos (T), por triplicado: T1, con Canavalia ensiformis + suelo; T2, con Vigna radiata + suelo; y T3, con suelo de control. Los parámetros de respuesta fueron la tasa de mineralización ( $\mathrm{mg}$ de $\mathrm{C}-\mathrm{CO}_{2}$ ) y cuantificación de células viables en unidades formadoras de colonias por gramo de suelo (UFC/g), para seis tiempos en 42 días. Se encontró que Vigna radiata obtuvo mayor tasa de mineralización (1,68 mg de $\left.\mathrm{C}_{-} \mathrm{CO}_{2}\right)$ y mayor dinámica poblacional $\left(2,73 \times 10^{13} \mathrm{UFC} / \mathrm{g}\right.$ de suelo), comparada con Canavalia ensiformis. Se obtuvieron nódulos y, al realizar la siembra en el agar LMA-RC, se confirmó la presencia de Rhizobium spp. en Vigna radiata. Se determinó la correlación entre la dinámica poblacional microbiana y la tasa de mineralización en los tres tratamientos, que resultó mayor para Canavalia ensiformis $(0,98)$. El estudio permitió concluir que las leguminosas evaluadas son viables en la zona analizada.
\end{abstract}

Palabras clave: abonos verdes; actividad microbiana; leguminosas; población microbiana; suelo

Recibido: 14 de noviembre de 2020

Aceptado: 09 de abril de 2021

Disponible en línea: 19 de noviembre de 2021

Cómo citar: P. A. Pérez Caicedo y L. Figueroa Del Castillo, «Evaluación de Canavalia ensiformis y Vigna radiata como abonos verdes, sobre la dinámica microbiana del suelo de la finca El Plan de Burras, en el municipio de El Espino, Boyacá, Colombia», Rev. Fac. Cienc. Básicas, vol. 17, n. 1, pp. 27-40, nov. 2021.

* Artículo de investigación.

a Ingeniera Ambiental, Universidad El Bosque, Bogotá, Colombia.

Correo electrónico: pauperezc18@gmail.com ORCID: https://orcid.org/0000-0001-9854-1400

b M. Sc. Ciencias Agrarias-Suelos y Aguas. Especialista en docencia de Biología y docencia mediada por TIC. Bióloga. Profesora e investigadora del Grupo de Ciencias Planetarias y Astrobiología (GCPA), Universidad Nacional de Colombia. Universidad El Bosque, Bogotá, Colombia.

Correo electrónico: Ifigueroac@unbosque.edu.co ORCID: https://orcid.org/0000-0003-2326-6904 


\title{
Evaluation of Canavalia Ensiformis and Vigna Radiata as Green Fertilizers, the Soil Microbial Dynamics of El Plan de Burras Farm, in the Municipality of El Espino, Boyacá, Colombia
}

\begin{abstract}
Summary: the capacity of legumes as green fertilizers is recognized and continues to be the subject of numerous studies. For this reason, in the first half of 2017, the effect of Canavalia ensiformis and Vigna radiata as green fertilizers was evaluated on the soil microbial dynamics, with no history of use for seven years, at El Plan de Burras farm, in El Espino, Boyacá, Colombia. The current condition was evaluated by using physicochemical parameters: pH (6.2) cation exchange capacity (21.97 mEq/100 g); organic matter (3.06\%); total carbon (1.77\%) and total nitrogen (0.15\%). The soils were subjected to three treatments (T), in triplicate: T1: with Canavalia ensiformis + soil; $\mathrm{T2}$ : with Vigna radiata + soil; and T3: with control soil. The response parameters were the mineralization rate $\left(\mathrm{mg}\right.$ of $\left.\mathrm{C}-\mathrm{CO}_{2}\right)$ and the quantification of viable cells in colony-forming units per gram of soil (cfu/g), for six times in 42 days. It was found that Vigna radiata obtained a higher mineralization rate $\left(1.68 \mathrm{mg}\right.$ of $\left.\mathrm{C}-\mathrm{CO}_{2}\right)$ and a higher population dynamics $(2.73 \times 1013 \mathrm{cfu} / \mathrm{g}$ of soil), compared to Canavalia ensiformis. Nodules were obtained and, when the agar was planted LMA-RC, the presence of Rhizobium spp. in Vigna radiata was confirmed. The correlation between microbial population dynamics and the rate of mineralization in the three treatments was determined, which was higher for Canavalia ensiformis (0.98). The study concluded that the legumes evaluated are viable in the area analyzed.
\end{abstract}

Keywords: green manure; microbial activity; legumes; microbial population; soil

Avaliação de Canavalia ensiformis e Vigna radiata como adubos verdes, sobre a dinâmica microbiana do solo da fazenda El Plan de Burras, no município de El Espino, Boyacá, Colômbia

Resumo: a capacidade das leguminosas como adubos verdes é reconhecida e continua sendo objeto de inúmeros estudos. Por isso, no primeiro semestre de 2017, foi avaliado o efeito de Canavalia ensiformis e Vigna radiata como adubos verdes, sobre a dinâmica microbiana do solo, sem histórico de uso por sete anos, da fazenda El Plan de Burras, em El Espino, Boyacá, Colômbia. Foi avaliado o estado atual por meio dos parâmetros físico-químicos pH $(6,2)$, capacidade intercâmbio catiônico $(21,97 \mathrm{mEq} / 100 \mathrm{~g})$, matéria orgânica $(3,06 \%)$, carbono total $(1,77 \%)$ e nitrogênio total $(0,15 \%)$. Os solos foram submetidos a três tratamentos ( $\mathrm{T}$ ), por triplicado: T1, com Canavalia ensiformis + solo; T2, com Vigna radiata + solo; T3, com solo de controle. Os parâmetros de resposta foram a taxa de mineralização ( $\mathrm{mg}$ de $\mathrm{C}-\mathrm{CO}_{2}$ ) e quantificação de células viáveis em unidades formadoras de colônias por grama de solo (ufc/g), para seis tempos en 42 dias. Constatou-se que Vigna radiata obteve maior taxa de mineralização (1,68 mg de C-CO ${ }_{2}$ ) e maior dinâmica populacional (2,73×1013 ufc/g de solo), comparada com Canavalia ensiformis. Foram obtidos nódulos e, ao realizar a semeadura no ágar LMA-RC, foi confirmada a presença de Rhizobium spp. em Vigna radiata. Foi determinada a correlação entre a dinâmica populacional microbiana e a taxa de mineralização nos três tratamentos, que resultou maior para Canavalia ensiformis $(0,98)$. Este estudo permitiu concluir que as leguminosas avaliadas são viáveis na área analisada.

Palavras-chave: adubos verdes; atividade microbiana; leguminosas; população microbiana; solo 


\section{Introducción}

En términos generales, los abonos verdes son plantas que se cultivan e incorporan in situ, con el fin de preservar, mejorar o restaurar las propiedades físicas, químicas y biológicas del suelo [1] y prolongar la salud y la calidad de este elemento. Todos los residuos de origen vegetal y animal que llegan al suelo conforman su materia orgánica, cuya principal fuente son los residuos vegetales, los cuales aportan energía y alimento a los organismos que conviven allí. Además, son la materia prima para la formación de los coloides orgánicos (humus) que se acumulan en el suelo [2].

Mediante la transformación del humus, se produce un enriquecimiento de la relación nitrógeno-carbono, como consecuencia del proceso de degradación microbiana, en el cual parte del carbono es transformado en $\mathrm{CO}_{2}$, medible como la actividad respiratoria, interpretada como un reflejo de la actividad metabólica de los microorganismos residentes en determinado hábitat, los cuales indican la dinámica de su biota, ya que los procesos metabólicos que se desarrollen allí pueden variar en función de factores biofísicos, climáticos y de uso de la tierra [3].

La función fundamental de los abonos verdes es complementar la nutrición de los cultivos en rotación; a través de la fijación de nitrógeno libre o por su eficacia en hacer que distintos nutrientes estén disponibles para los cultivos, nutrientes que, de otra manera, serían inaccesibles. Una de las maneras de lograr esto es a través de la fertilización nitrogenada [4].

Dentro del grupo de los abonos verdes, se encuentran las leguminosas, cuya principal función es, justamente, fijar nitrógeno al suelo. El nitrógeno es uno de los elementos esenciales en la nutrición de las plantas [5]. Su fijación biológica se da en los nódulos radiculares, los cuales son resultado de la perfecta relación de simbiosis entre la planta y las bacterias [6].

Es importante destacar que, con el tiempo, han venido buscándose alternativas de manejo para mejorar la fertilidad de los suelos cultivados. Por ende, se han usado tecnologías agroecológicas como los abonos verdes, cuyos aportes investigativos a nivel mundial buscan generar una base teórica que explique la importancia de su aplicación y potencialidades dentro del manejo de los agroecosistemas [1].

El uso con ese propósito de la leguminosa $\mathrm{Ca}$ navalia ensiformis ha sido reportado por García et al. [7], quienes resaltan el incremento logrado con ella de 1,36 a 1,84\% de los contenidos de materia orgánica en el suelo. Por su parte, Sánchez et al. [8] evaluaron varias leguminosas, entre ellas Canavalia ensiformis, la cual presentó altas cantidades en la producción de materia seca y fácil adaptabilidad a las condiciones edafoclimáticas de la región. Estudios similares, efectuados por Ángel y Prager [9], evidencian que las leguminosas Canavalia, Crotalaria y Guandul no presentaron problemas fitosanitarios, ni deficiencias nutricionales en el tiempo transcurrido de la siembra a la floración; y tuvieron un aumento en la nodulación al avanzar su ciclo vegetativo. Así también, Marmolejo et al. [10] reportaron que Canavalia e. presenta una buena nodulación con una distribución uniforme y de gran abundancia.

En cuanto a Vigna radiata, Búcaro y Mejía [11] la recomiendan como mejoradora de suelos y sugieren que, a nivel nutricional, evita la pérdida de elementos como potasio y fósforo. Asimismo, determinaron su efectividad en la nodulación con valores del aporte de nitrógeno 2,44 y 2,97\%. A este se suma el estudio de Benavides y Marvin [12], en el cual el fríjol mungo (Vigna radiata) fue la única entrada de nutrientes en el suelo y aportó grandes cantidades de nutrientes (NPK), que lograron suplir las necesidades nutritivas tanto de cultivos como del suelo. Al utilizar fríjol mungo como fuente de nitrógeno, la absorción fue mejor, lo cual se expresa en términos de rendimiento del grano.

Finalmente los abonos verdes son estrategias agroecológicas a través de las cuales pueden aumentarse las ventajas comparativas que propicien la seguridad, soberanía alimentaria y la fertilidad natural de los suelos; a su vez, permiten recuperar algunos nutrientes, pues la incorporación y posterior degradación de los abonos aumenta el fósforo disponible para el siguiente cultivo, ya que produce un incremento en el número de los 
microorganismos y de su actividad de disolver compuestos inorgánicos insolubles de fósforo.

A ello se suma que los abonos verdes disminuyen o anulan la erosión, que significa la pérdida de la capa superficial, donde se encuentra buena parte de los nutrientes y la materia orgánica. Sin embargo, esta práctica no solo genera beneficios ambientales, sino también socioeconómicos, por ser alternativas sostenibles y aplicables a cualquier cultivo. Finalmente, estos tipos de abono son fáciles de adquirir, de precios bajos y de crecimiento rápido, en alturas superiores a $900 \mathrm{msnm}$.

Por lo anterior, en este trabajo se consideró importante evaluar el efecto de Canavalia ensiformis y Vigna radiata como abonos verdes, ya que se reportan de fácil adaptabilidad a la zona y de rápido crecimiento, sobre la dinámica microbiana del suelo de la finca El Plan de Burras, ubicada en el municipio de El Espino del departamento de Boyacá, Colombia; finca sin historial de uso por siete años y que antes había sido usada para cultivo de tabaco, durante veinte años. El interés de la investigación estuvo centrado en mejorar y potencializar las condiciones del recurso suelo, para que pueda volver a ser usado de forma sostenible, mediante el seguimiento de la dinámica de la población microbiana durante la mineralización por 42 días.

\section{Materiales y métodos}

\section{Muestreo de suelos}

El estudio fue desarrollado en la finca El Plan de Burras, ubicado en el municipio de El Espino, provincia de Gutiérrez, al nororiente del departamento colombiano de Boyacá, sobre la Cordillera Oriental (figura 1), localizada en la longitud $78^{\circ} 32^{\prime} 2,33^{\prime \prime}$ y latitud $6^{\circ} 29^{\prime} 25,93^{\prime \prime}$, a una altura de $1773 \mathrm{msnm}$.

En el municipio de El Espino, predomina el clima frío con temperaturas que oscilan en el rango de $4-12^{\circ} \mathrm{C}$. Existen pequeñas franjas transicionales de los climas templado y cálido seco, cuyas temperaturas oscilan entre los $12-18{ }^{\circ} \mathrm{C}$ y los 18 $24{ }^{\circ} \mathrm{C}$, respectivamente [13]. Finalmente, la finca se encuentra en una franja transicional de clima cálido seco.

Al desarrollar la investigación, con el fin de determinar el estado actual del suelo, se obtuvo una muestra de $30 \mathrm{~kg}$ de suelo, tomados a manera de zigzag, para abarcar la totalidad de las 20 hectáreas del terreno (figura 2). El terreno es de relieve homogéneo y tiene una profundidad de $20 \mathrm{~cm}$ [14]. Una parte de las muestras fue enviada al Laboratorio de Suelos del Instituto Geográfico Agustín Codazzi (Igac), ubicado en Bogotá, Colombia; y otra parte del suelo muestreado se utilizó en la fase experimental.

Los suelos de la zona de estudio son moderadamente profundos, bien drenados y de reacción fuertemente ácida; su clasificación taxonómica corresponde a un Humic Dystrustepts (MMEg), que se localizan en los entalles de las laderas; la nomenclatura del perfil corresponde a A/B/Cr. Son de resaltar algunas características que predominan en el horizonte A, como un espesor de $58 \mathrm{~cm}$, colores pardo oscuro y gris muy oscuro; textura franco-arcillosa y arcillosa, estructura en bloques subangulares, moderados a fuertes. En cuanto al horizonte $\mathrm{B}$, es de color pardo oscuro con manchas de color pardo fuertes y textura arcillosa. Finalmente, el horizonte $\mathrm{Cr}$ contiene el mineral lutita, en proceso de alteración [15].

En cuanto al historial de uso, no se registra por más de siete años, después de haber sido utilizado por veinte años para la siembra de tabaco, cultivo tradicional de la zona estudiada. Al respecto, cabe mencionar que la producción de tabaco genera grandes efectos ambientales, ya que durante el cultivo se consume once veces más nitrógeno del suelo de lo que lo hace una cosecha, así como 36 veces más fósforo y veinte veces más potasio [16].

En el laboratorio de suelos del Igac, se evaluaron los parámetros fisicoquímicos: $\mathrm{pH}$, textura, capacidad de intercambio catiónico, carbono total, materia orgánica, nitrógeno total, saturación de bases y fósforo disponible.

Simultáneamente, se realizaron la fase de campo y la fase experimental en el Laboratorio de Microbiología de la Universidad El Bosque, en 
COLOMBIA

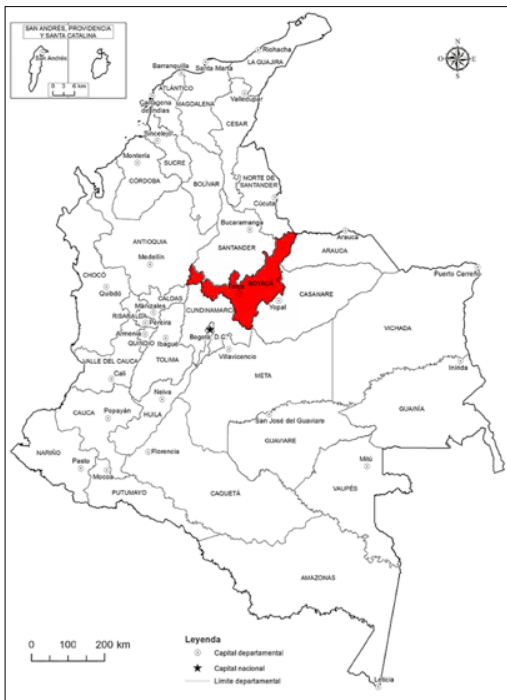

BOYACÁ

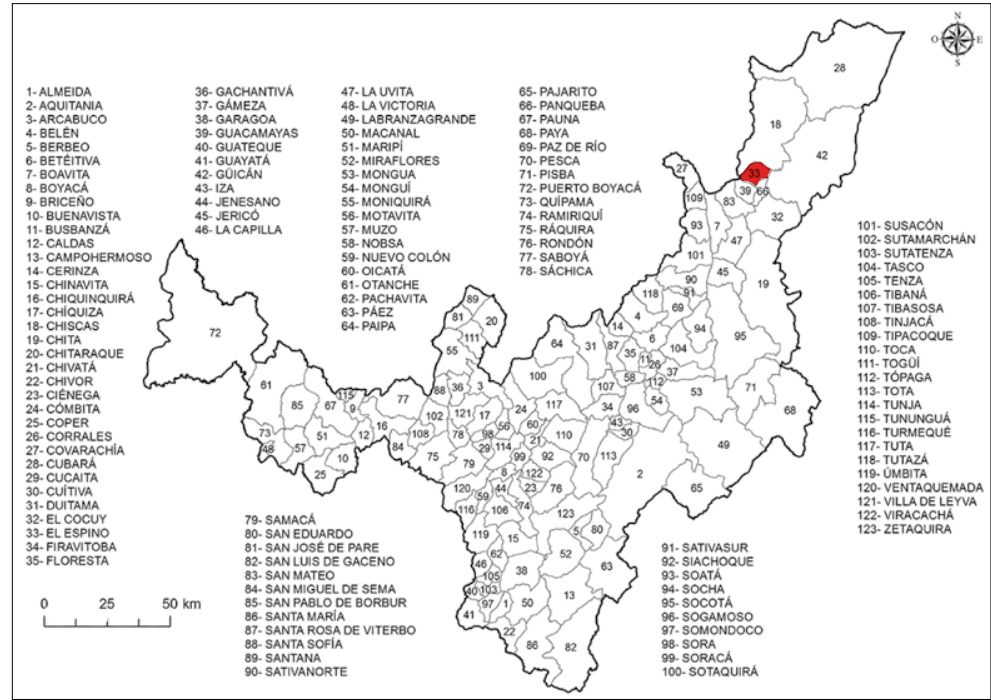

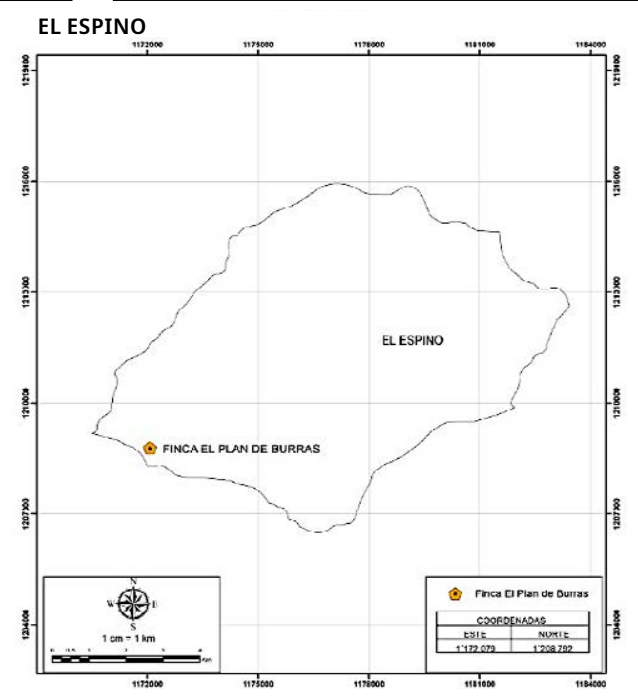

Figura 1. Localización de la finca El Plan de Burras, en el municipio de El Espino, Boyacá, Colombia.

Fuente: elaboración propia con ArcGis. https://www.mapasparacolorear.com/

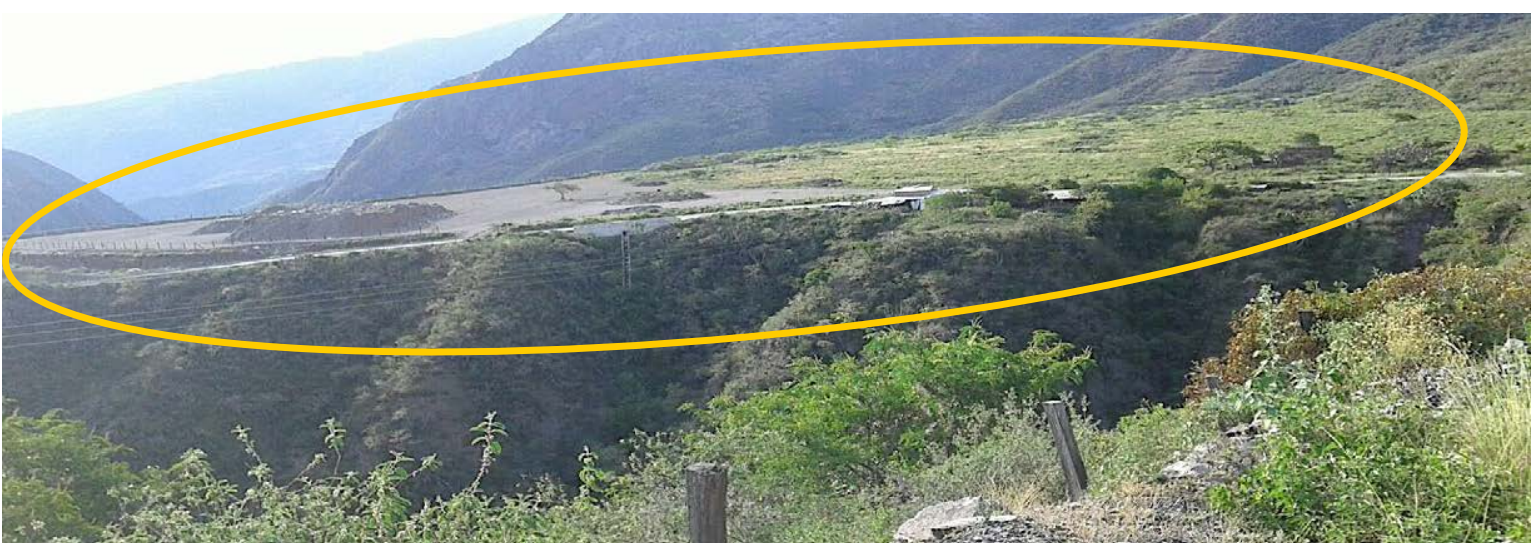

Figura 2. Área de muestreo (en amarillo) de suelos en la finca El Plan de Burras, municipio de El Espino, Boyacá, Colombia.

Fuente: elaboración propia. 
Bogotá, Colombia, en condiciones controladas. Entretanto, en la finca El Plan de Burras fueron implementados en materas por siembra directa y por triplicado, los siguientes tratamientos $(\mathrm{T})$ :

- T1: Suelo + Canavalia ensiformis

- T2: Suelo + Vigna radiata

- T3: Suelo de control

Se establecieron seis tiempos en los días $1,4,7$, 13,29 y 42 , equivalentes a los muestreos $1-6$, respectivamente. Se tomaron datos como mineralización de carbono y recuento de células viables, representado en unidades formadoras de colonia por gramo de suelo (UFC/g de suelo).

Al finalizar la fase experimental, en el día 42, se realizó en las leguminosas evaluadas el conteo de nódulos, la medición de diámetro y la siembra en Agar Manitol Extracto de Levadura-Rojo de Congo (LMA-RC), para recuento del género bacteriano Rhizobium.

\section{Mineralización del suelo}

Para el experimento de mineralización, se cuantificó la formación de $\mathrm{CO}_{2}$, a partir de los tratamientos establecidos [17]-[20]. Para cada muestreo, se realizaron mediciones de la cantidad de $\mathrm{NaOH}$ no neutralizado, mediante titulación con $0,1 \mathrm{M}$ de $\mathrm{HCl}$ (en cada ocasión se reemplazó la trampa de $\mathrm{CO}_{2}$ por una nueva).

Para la titulación de la solución, se extrajo 01 $\mathrm{ml}$ de $\mathrm{NaOH}$, al que se adicionaron $02 \mathrm{ml} \mathrm{de} \mathrm{BaCl}_{2}$, para precipitar el carbono (C) inorgánico como $\mathrm{BaCO}_{3}$ insoluble. Finalmente, se adicionaron gotas de fenolftaleína como indicador, y se tituló el $\mathrm{NaOH}$, no neutralizado, directamente con $\mathrm{HCl}$.

El procedimiento fue modificado debido a que, de acuerdo con varios autores, se indican diferentes pesos y molaridades en los reactivos. De ese modo, se incorporaron $10 \mathrm{~g}$ de suelo en frascos de vidrio tipo Marson Jars. Se utilizaron nueve frascos, para cada repetición por leguminosa (3) y para el control (3). Se incorporaron tubos de ensayo, cada uno con $06 \mathrm{ml}$ de $\mathrm{NaOH} 0,1 \mathrm{M}$ y $10 \mathrm{~g}$ de suelo. Al realizar la titulación, se tomó $\mathrm{HCl} 0,1$ M y se utilizó $\mathrm{BaCl}_{2} 1,25 \mathrm{M}$. Para los cálculos, se utilizó la ecuación de Stotzky (1965; ecuación 1) y los resultados se expresaron en unidades de $\mathrm{mg}$ de C- $-\mathrm{CO}_{2}[21]$.

$m g C-\mathrm{CO}_{2}=(B-T) \times e q \times M$

Donde:

$\mathrm{B}=$ volumen $(\mathrm{ml})$ de la solución de $\mathrm{HCl}$ gastado para titular la prueba en el blanco.

$\mathrm{T}=$ volumen $(\mathrm{ml})$ de la solución de $\mathrm{HCl}$ gastado para titular los tratamientos.

$\mathrm{Eq}=$ equivalente en gramos de carbono (6). $\mathrm{M}=$ molaridad de la solución estándar de $\mathrm{HCl}$.

\section{Cuantificación de la población microbiana cultivable durante la mineralización}

En paralelo con la medición de la tasa de mineralización de carbono, se extrajo una muestra de suelo de cada uno de los frascos, sellados herméticamente para evitar la entrada de oxígeno, en los seis tiempos, en los días 1, 4, 7, 13, 29 y 42, equivalentes a los muestreos 1-6, respectivamente, para realizar el recuento de poblaciones bacterianas en el medio Plate Count Agar (PCA) en series de dilución hasta 1011 y siembra en la superficie, por triplicado. Posteriormente, las muestras fueron incubadas a una temperatura de $22{ }^{\circ} \mathrm{C}$ por 48 horas y se registró el número de unidades formadoras de colonias (UFC) hasta 300 [22].

Para obtener el resultado de las UFC, se calcula la relación del producto del número de colonias por la dilución con el peso de la muestra de suelo, en unidades de UFC/g de suelo, según la ecuación 2 [22].

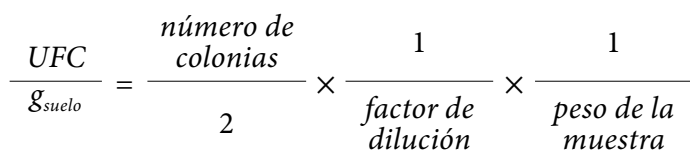

Según Vinuesca [23], la correlación se define en términos de la varianza $\left(\mathrm{s}^{2}\right)$ de las variables $x, y$, así como de la covarianza (cov) de $x, y$. Por tanto, es una medida de la variación conjunta de ambas variables, es decir, $\operatorname{cov}(x, y)$ :

- Varianza sª la varianza de una muestra representa el promedio de la desviación de los datos con respecto a la media, como se observa en la ecuación 3. 


$$
\operatorname{varianza}\left(s^{2}\right)=\frac{\sum\left(x_{i}-x\right)^{2}}{N-1}=\frac{\sum\left(x_{i}-x\right)\left(x_{i}-x\right)}{N-1}
$$

- Covarianza cov $(x, y)$ : la covarianza entre dos variables $x, y$ es una medida de su relación promedio; es la desviación promedio del producto cruzado entre ellas, de acuerdo con la ecuación 4.

$$
o v(x, y)=\frac{\sum\left(x_{i}-x\right)\left(y_{i}-y\right)}{N-1}
$$

\section{Crecimiento de las leguminosas}

Las leguminosas seleccionadas para el presente estudio se tomaron en cuenta dado que promueven el aumento de nitrógeno, carbono orgánico (co) y materia orgánica que, probablemente, pueden estar en bajas condiciones por el manejo y el historial de uso del suelo. También porque se ha establecido que Canavalia ensiformis y Vigna radiata crecen en la zona de estudio. Ambas se recolectaron al final del experimento, correspondiente al día 42. Con la recolección, se realizó el conteo y medición del diámetro de los nódulos y se determinó el porcentaje de la materia seca del material vegetal, el cual fue sometido en la mufla por 24 horas [19].

\section{Fijación biológica de nitrógeno}

El empleo de las leguminosas tiene el objetivo principal de aportar nitrógeno adicional al suelo y los cultivos subsiguientes. Estas plantas fijan el nutriente desde el aire, debido a su asociación simbiótica con el género bacteriano Rhizobium spp., que forma nódulos en la raíz de la leguminosa, donde se lleva a cabo la fijación del nitrógeno atmosférico. Pero, la presencia de nitrógeno mineral, principalmente nitratos, perjudica la formación de los nódulos [4].

Una vez obtenidos los nódulos, se procedió a reconocer las bacterias del género Rhizobium, a partir de la desinfección de los nódulos por inmersión sucesiva en alcohol al $95 \%$ por un minuto. Posteriormente, se desinfectaron en hipoclorito de sodio al $3 \%$ durante tres minutos; finalmente los nódulos se enjuagaron con agua destilada [24].

Tan pronto como se desinfectaron, los nódulos se pusieron en otro mortero, donde se trituraron adicionando una gota de agua destilada por nódulo. Enseguida, las muestras del material macerado fueron sembradas por estría en placa de Agar Manitol Extracto de Levadura-Rojo de Congo (LMA-RC), se incubaron a $28^{\circ} \mathrm{C}$ por 24 horas y, finalmente, se realizó tinción de Gram [24].

\section{Resultados y análisis}

\section{Propiedades fisicoquímicas del suelo}

En la tabla 1, se observan los resultados obtenidos de las propiedades fisicoquímicas del suelo evaluado (Igac, 2017). Con estos datos, se realizó un comparativo con los análisis de suelos del año 2012 (Agrilab), con el fin de establecer las diferencias del

Tabla 1. Resultados de las propiedades fisicoquímicas, del suelo evaluado y comparativo Agrilab (2012)

\begin{tabular}{|l|l|c|c|}
\hline Parámetro & Método & Agrilab 2012 & Igac 2017 \\
\hline $\mathrm{pH}$ & Potenciométrico 1:1 & Franco arcillosa & Franco arcillosa \\
\hline Textura & Bouyoucos & 22,27 & 21,97 \\
\hline CIC (cmol/kg) & Acetato de amonio 1 N pH 7 & NR & 1,77 \\
\hline CO (\%) & Walkley Black modificado & 3,65 & 3,06 \\
\hline MO (\%) & Walkley Black modificado & 0,18 & 0,15 \\
\hline NT (\%) & Kjeldahl & 100,04 & 71,48 \\
\hline SB (\%) & Acetato de amonio 1 N pH 7 - cuantificación absorción atómica & 67,13 & 50,66 \\
\hline PD & Bray II & 2 \\
\hline
\end{tabular}

cIC: Capacidad de intercambio catiónico; co: carbono orgánico; MO: materia orgánica; NT: nitrógeno total; SB: saturación de bases; PD: fósforo disponible; NR: no registrado.

Fuente: elaboración propia. 
estado actual del suelo con el historial de uso del recurso.

Como se observa en la tabla 1, hay una ligera variación del pH de 7,1 a 6,2, es decir, el suelo pasó de neutro a ligeramente ácido. Según Osorio, los suelos se acidifican por diversos factores, entre los cuales sobresale la meteorización de minerales aluminosilicatos y la consecuente liberación de aluminio $\left(\mathrm{Al}^{3+}\right)$ a la solución del suelo [25].

Otra causa de este cambio en el $\mathrm{pH}$ puede ser que en 2017 el suelo no venía presentando historial de uso; mientras que en 2012 era más cercano al anterior a 7,1, por historial uso del suelo (monocultivo de tabaco), tiempo durante el cual se realizaron aportes de fertilizantes y enmiendas como el encalado. Es decir, debido a que el suelo no tuvo entradas en su sistema, es posible que ello pudiera repercutir en la disminución de los valores del pH para 2017.

De acuerdo con lo obtenido en la tabla 1, la textura del suelo es franco-arcillosa. Según lo indicado por el Igac, la granulometría del suelo es arena $(44,9 \%)$, limo $(36,2 \%)$ y arcilla $(36,2 \%)$. Al presentar una textura franca, tiene mayor equilibrio entre sus componentes, con efectos favorables, puesto que ese es el estado ideal del suelo [18]. Además, el aumento de la fracción de arcilla conduce a un aumento de la cohesión, la plasticidad y la adhesividad [26]. Todo ello permite un equilibrio entre la permeabilidad al agua, retención de agua y nutrientes.

La capacidad de intercambio catiónico (CIC) se define como la habilidad del suelo para retener y liberar iones positivos [27]. Con los datos mostrados en la tabla 1 , se determina que el valor de la CIC es de 21,971 mEq/100 g. La carga que depende del $\mathrm{pH}$ ocurre por rupturas en la periferia de los cristales de los minerales; además, los suelos ácidos pueden desarrollar carga positiva y, por tanto, alcanzar capacidad de intercambio aniónico [28].

La cic depende de la textura y del $\mathrm{pH}$ del suelo. Según el Servicio Agronómico Americano, los valores medios para suelos arcillosos de $20 \mathrm{mEq} / 100 \mathrm{~g}$ [29]. Con este dato, puede afirmarse que el suelo objeto de estudio es arcilloso, puesto que la cic es $21,971 \mathrm{mEq} / 100 \mathrm{~g}$, lo cual indica que se acerca al valor establecido.
La materia orgánica tiene un papel importante: regula los procesos químicos que ocurren allí, influye sobre las características físicas y es el centro de casi todas las actividades biológicas con las que se relaciona, incluyendo las de la microflora, las de la fauna y hasta las del sistema de raíces de plantas superiores [27].

Por otro lado, se presenta una pérdida de materia orgánica, la cual puede darse por una degradación química la cual puede ser definida como la pérdida de nutrientes (o la acumulación excesiva de algún nutriente) y el aumento de la salinidad o la acidez. La degradación del suelo no es sino la reducción de su capacidad para mantener una productividad sostenida, en otras palabras, su capacidad para recuperar rápidamente los niveles anteriores de producción o retomar la tendencia de una productividad en aumento después de un periodo adverso a causa de sequías, inundaciones, abandono o mal manejo humano, entre otros factores [30].

Según Múnera y Meza [31] la concentración del fósforo en la solución del suelo es importante en la nutrición vegetal, debido a que las raíces de las plantas absorben fósforo de esta solución, además es un nutriente esencial y principal para el crecimiento de las plantas, puesto que ayuda a las raíces a desarrollarse rápidamente, aumenta la eficiencia del uso del agua, acelera la madurez de la cosecha, aumenta la resistencia a las enfermedades en algunas plantas y es indispensable para la transferencia energética. En el suelo objeto de estudio, se obtuvo fosforo disponible de $50,66 \mathrm{cmol} / \mathrm{kg}$, lo cual significa que es alto (rango mayor de 40).

\section{Mineralización del suelo}

La evolución de la tasa de mineralización de carbono (figura 3), para los tratamientos T1 y T2 fue diferente entre estos y con respecto al control. El primer tratamiento obtuvo la mayor tasa de mineralización en el muestreo 4 , correspondiente al día 13 , con un valor de $1,02 \mathrm{mg}$ de $\mathrm{C}-\mathrm{CO}_{2}$, para estabilizarse después, hasta el final del experimento. Mientras tanto, en el segundo tratamiento (T2) la mayor tasa de mineralización fue para el muestreo 5 , correspondiente al día 29 , con un valor de $1,56 \mathrm{mg}$ de $\mathrm{C}-\mathrm{CO}_{2}$, el cual tiende a estabilizarse hasta el 
final del experimento. Cabe anotar, que de los tratamientos evaluados el segundo presentó mayor tasa de mineralización, en comparación con el primero.

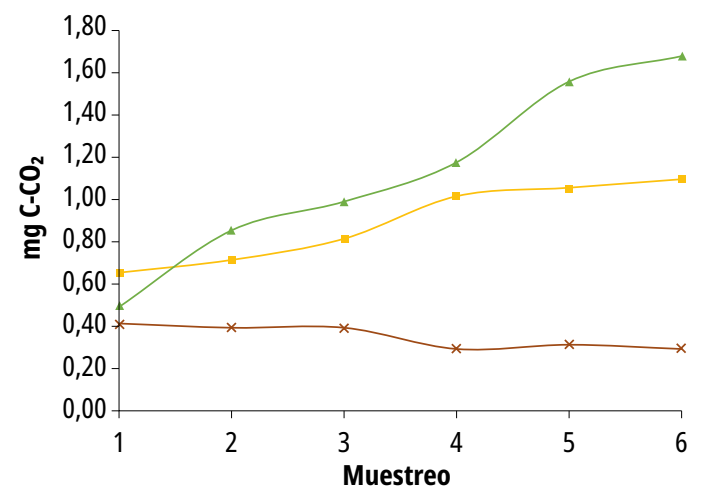

$$
\begin{aligned}
& \ldots \text { T1: Suelo + Canavalia ensiformis } \\
& \ldots \text { T2: Suelo + Vigna radiata } \\
& \ldots \quad \text { T3: Control (suelo) }
\end{aligned}
$$

Figura 3. Evolución de la tasa de mineralización de los tratamientos evaluados.

Fuente: elaboración propia.

Por ser la tasa de liberación de $\mathrm{CO}_{2}$, la mineralización toma como punto de origen a la materia orgánica fresca que se presenta en una etapa muy activa, que corresponde, a su vez, a la liberación de materiales orgánicos lábiles (azúcares, amino-azúcares, aminoácidos y ácidos orgánicos), seguida de una segunda etapa, cuando la actividad biológica decrece [20].

La especie Vigna radiata presentó mayor mineralización y mayor crecimiento en la dinámica poblacional. Según Bogado [3], la actividad respiratoria puede ser interpretada como un reflejo de la actividad metabólica de los microorganismos residentes en determinado hábitat, los cuales indican la dinámica de su biota, ya que los procesos metabólicos que se desarrollen allí pueden variar en función de factores biofísicos, climáticos y de uso de la tierra.

Cabe anotar que para los tratamientos $\mathrm{T} 1$ y $\mathrm{T} 2$, no se visualizó la descendencia en la curva; a diferencia de lo que ocurrió con el tratamiento T3 de control. Al no haber materia orgánica, tampoco tiene lugar el proceso de mineralización. Por otro lado, es importante recordar que el suelo evaluado estaba desprovisto de cobertura vegetal, lo cual se suma al valor medio obtenido de carbono orgánico $\mathrm{y}$ al factor clima que predomina en la zona.

\section{Relación entre la población microbiana cultivable y el proceso de mineralización}

En la figura 4, se observan los cambios en el tamaño de las poblaciones microbianas cultivables (uFC/g de suelo) para los tres tratamientos, en los en tiempos evaluados. Los tratamientos T1 y T2 muestran incremento de las UFC, en comparación con el suelo de control, cuya tendencia fue baja y estable.

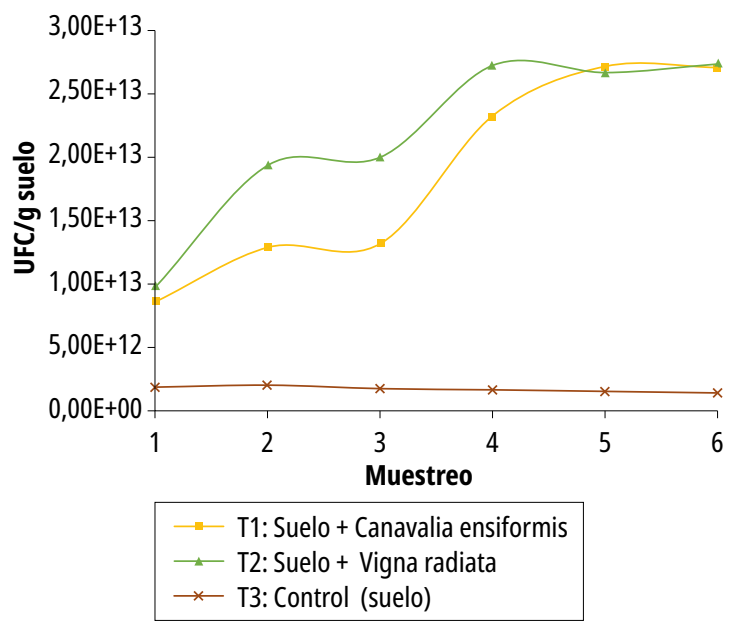

Figura 4. Dinámica de la población microbiana (UFC/g de suelo) en los tres tratamientos en los seis muestreos del suelo evaluado.

Fuente: elaboración propia.

La dinámica de aumento de crecimiento poblacional en los tratamientos T1 y T2 puede ocurrir por la presencia de las raíces de las leguminosas que activan la actividad microbiana [32]. Al respecto se obtuvo que la leguminosa Vigna radiata tuvo mayor crecimiento de UFC/g, en comparación con Canavalia ensiformis, debido a la probable habilidad que las plantas poseen en su rizodeposición, que es una gama de moléculas de alto y bajo peso molecular, que produce mayor proliferación de microorganismos dentro (endorrizósfera), sobre (rizoplano) y alrededor de la raíz (ectorizósfera) [33]. Con lo cual es posible afirmar que, por un lado, la rizodeposición es diferente en cada 
leguminosa y, por otro, es probable que Vigna radiata hubiera producido mayor estímulo en los microorganismos.

De otro lado, el suelo de control no tuvo mayor crecimiento de UFC/g de suelo seco. Las limitaciones de la actividad bacteriana pueden ser impuestas por la disponibilidad de alimento, factores físicos como la humedad, la aireación, la reacción y temperatura; sumados a factores biológicos del ambiente [34]. Esto pudo suceder puesto que el suelo no contó con ningún tipo de intervención en todo el procedimiento.

En cuanto a la relación entre la población microbiana cultivable y el proceso de mineralización por tratamientos, en la figura 5, se evidencia la relación entre las UFC/g y la tasa de mineralización para Vigna radiata.

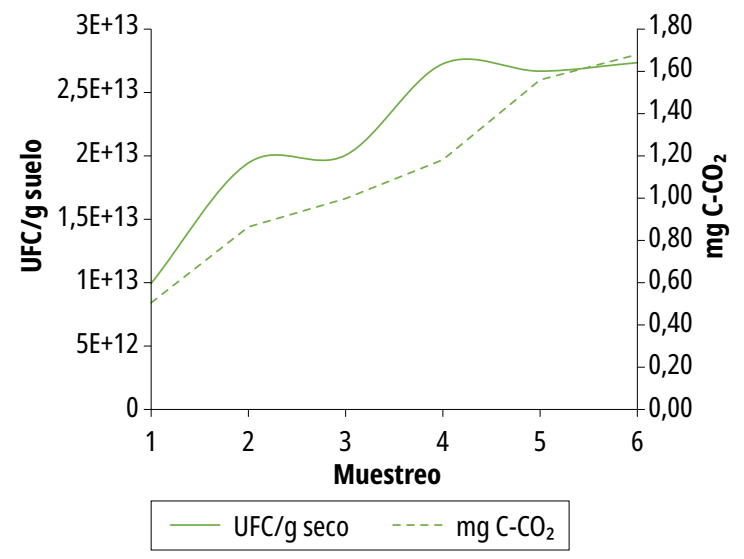

Figura 5. Relación entre UFC frente a mg de $\mathrm{C}-\mathrm{CO}_{2}$ de Vigna radiata en el suelo evaluado.

Fuente: elaboración propia.

En la figura 6, se observa la relación de estos dos parámetros, pero, esta vez, en la leguminosa Canavalia ensiformis. En estas dos gráficas, se obtuvo: (1) el crecimiento de las UfC/g y de la mineralización, lo cual confirma los resultados de Gallardo et al. [35]; (2) la abundancia de carbono orgánico y, consecuentemente, de nitrógeno en el suelo; y (3) que esta especie promueve un aumento de la diversidad y número de especies microbianas edáficas, al disponer más fácilmente de nutrientes y energía para su desarrollo vital.

Esta relación entre las UFC frente alC- $\mathrm{CO}_{2}$ ocurre porque el $\mathrm{CO}_{2}$ es liberado por los microorganismos, al realizar funciones metabólicas fundamentales como la obtención de ATP. Cuanto mayor sea la cantidad de gas liberado, más elevada es la actividad, y viceversa [35].

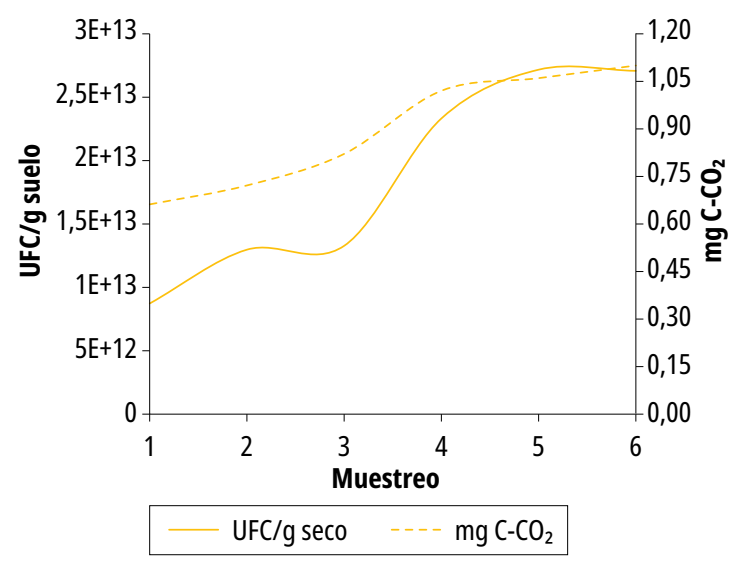

Figura 6. Relación entre UFC frente a mg de $\mathrm{C}-\mathrm{CO}_{2}$ de Canavalia ensiformis en el suelo evaluado.

Fuente: elaboración propia.

La correlación es una medida de la relación lineal entre dos variables cuantitativas continuas [22]. En este caso, se realizó un tratamiento de control, el cual nos permite verificar el cambio o la relación existente con los restantes dos tratamientos de abonos verdes estudiados.

La mayor correlación entre la tasa de mineralización y las UFC/g de suelo fue de 0,98, para el tratamiento T1, con leguminosa Canavalia ensiformis; mientras que para el tratamiento T2, con la leguminosa Vigna radiata, fue de 0,91 . Estos resultados señalan que la comunidad microbiana es la responsable directa del proceso de mineralización.

Se considera que la aplicación de abonos verdes a los suelos es una buena práctica ecológica de manejo dentro de cualquier sistema de producción agrícola, porque estimula el crecimiento y la actividad microbiana. Este estímulo, a su vez, lleva a la mineralización de los nutrientes necesarios para las plantas y, por tanto, incrementa la fertilidad y la calidad de los suelos en el largo plazo [36].

Finalmente, en el tratamiento T3 con el suelo control (figura 7), se observó la relación entre las variables UFC/g de suelo y tasa de mineralización, lo que arrojó un coeficiente de correlación de 0,87. Este resultado también muestra que ambas variables disminuyen con el paso de los días. 


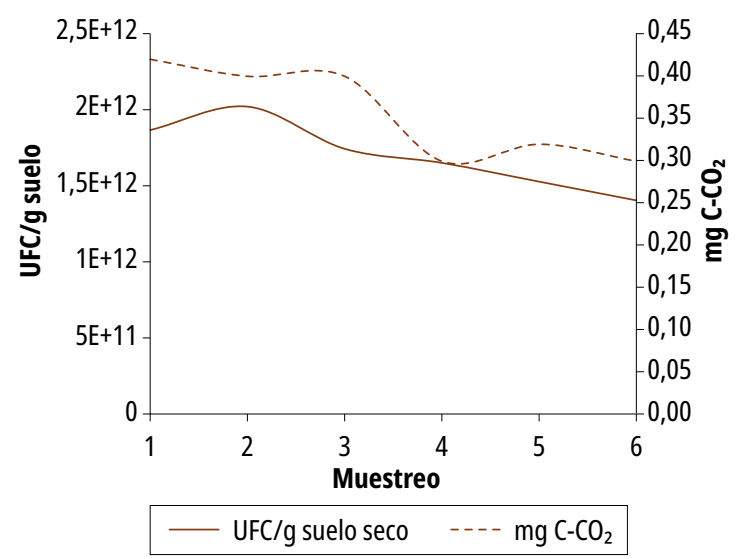

Figura 7. Relación entre UFC frente a mg C- $\mathrm{CO}_{2}$ del suelo evaluado (control).

Fuente: elaboración propia.

Según Bogado-Ferioli [3], el potencial de mineralización en el suelo depende de factores ambientales como la temperatura, la humedad, la aireación, el pH y la fertilidad; a los que se suma la adsorción a las arcillas, de enzimas y compuestos orgánicos. Al respecto, es importante anotar que el suelo evaluado en esta parte no estuvo en contacto con ningún tipo de cobertura vegetal, debido al manejo que ha venido dándose al recurso suelo en la zona de estudio, pues, como se dijo, permaneció sin uso por siete años.

\section{Crecimiento de las leguminosas}

Los resultados obtenidos del crecimiento de las leguminosas, una vez cumplido el tiempo de 42 días de la fase experimental, se evidencian en la tabla 2.

Al comparar las dos leguminosas, se obtuvo que los mayores valores para altura y número de nódulos fue para Canavalia ensiformis. Mientras que la leguminosa Vigna radiata obtuvo el mayor porcentaje de materia seca $(57,89 \%)$, lo que indica que, de acuerdo con García y Martínez [38], presenta valores altos de nitrógeno. Este resultado, es de gran importancia pues las plantas absorben del suelo nitratos y amonio que utilizan en la síntesis de las proteínas y de otros compuestos orgánicos vegetales [5].

El diámetro de los nódulos fue similar para ambas leguminosas; además, los nódulos tienen un tamaño regular, lo cual a menudo indica mayores tasas de fijación de nitrógeno, en comparación con la presencia de algunos pocos nódulos de gran tamaño [39].

\section{Fijación biológica de nitrógeno}

Para determinar la fijación biológica de nitrógeno, se tomaron en cuenta los resultados obtenidos del número de nódulos registrados en la tabla 2. Luego de realizar el procedimiento descrito en la sección “Fijación biológica de nitrógeno", se observó que el crecimiento fue efectivo para la leguminosa Vigna radiata (figura 8). Posteriormente, le realizada la tinción de Gram, lo que dio un resultado Gram negativo de tipo bacilar (figura 9). Esto confirma los resultados de Moreno-Conn [40], quien afirma que se trata del género Rhizobium.

El resultado de la simbiosis de Rhizobium spp. y leguminosa proporciona mayor cantidad de nitrógeno en los ecosistemas terrestres. Además, tiene gran impacto en términos agronómicos y ecológicos [41], pues favorece la calidad y la fertilidad del suelo [42] y aporta nutrientes como el nitrógeno, el potasio y el fósforo [43].

Tabla 2. Promedios en el crecimiento y número de nódulos de las leguminosas evaluadas

\begin{tabular}{|l|c|c|c|c|}
\hline Leguminosa & $\begin{array}{c}\text { Altura tallos } \\
(\mathbf{c m})\end{array}$ & $\begin{array}{c}\text { Materia seca } \\
(\%)\end{array}$ & $\begin{array}{c}\text { Número de } \\
\text { nódulos }\end{array}$ & $\begin{array}{c}\text { Diámetro de nódulos } \\
(\mathbf{m m})\end{array}$ \\
\hline Vigna radiata & 16,51 & 57,89 & 107 & $0,1-0,5$ \\
\hline Canavalia ensiformis & 19,82 & 25,60 & 130 & $0,1-0,4$ \\
\hline
\end{tabular}

Fuente: elaboración propia. 


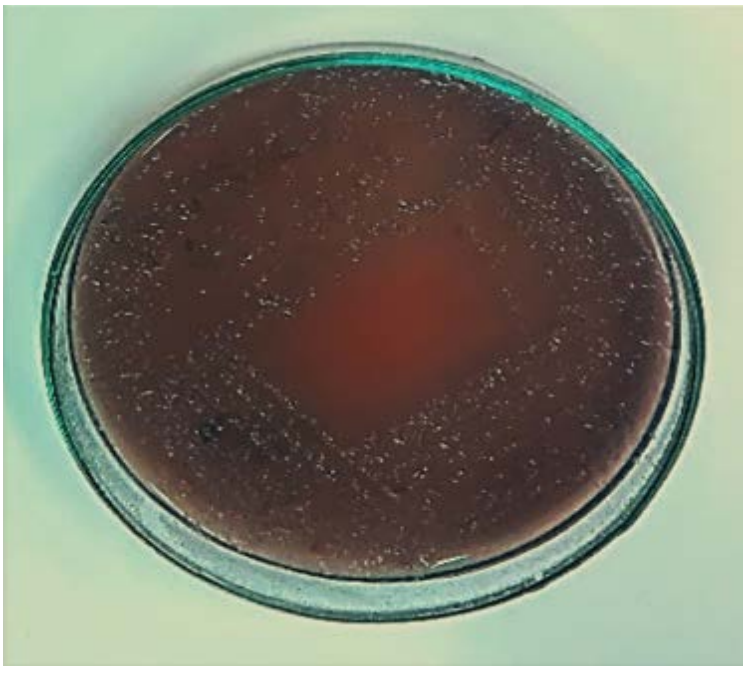

Figura 8. Crecimiento del género Rhizobium en Vigna radiata, en el agar LMA-RC.

Fuente: elaboración propia.

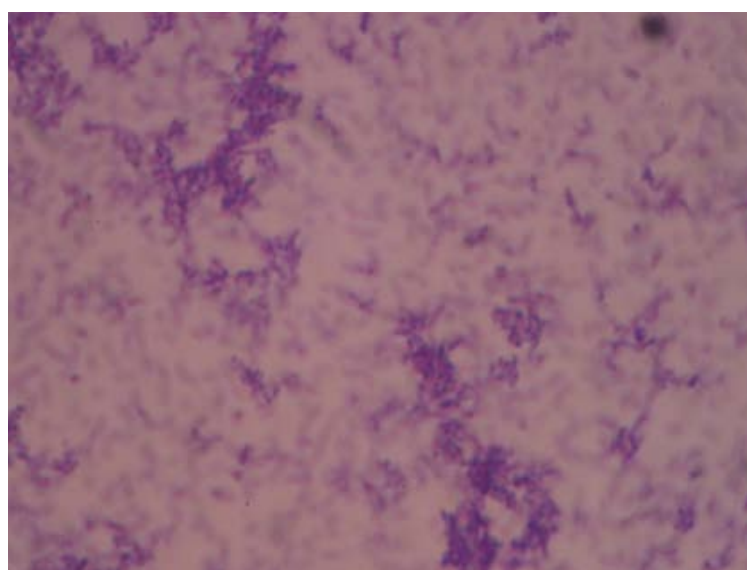

Figura 9. Tinción de Gram del género Rhizobium en Vigna radiata.

Fuente: elaboración propia.

\section{Conclusiones}

Los coeficientes de relación obtenidos para los tratamientos T1 de 0,98 (suelo + Canavalia ensiformis); T2 de 0,91 (suelo + Vigna radiata); y T3 de 0,87 (suelo de control), muestran una estrecha relación entre ambas variables, lo que implica que la población microbiana cultivable participa activamente en la mineralización del suelo de la finca El Plan de Burras, del municipio el Espino, en Boyacá, Colombia.
Después de que las leguminosas fueron evaluadas, se determinó que son viables para ser utilizadas en la zona de estudio para la protección, nutrición, mejoramiento y potencializado del recurso suelo.

De la evaluación de los tres tratamientos, el mayor incremento de poblaciones bacterianas $\left(2,73 \times 10^{13}\right)$ y tasa de mineralización $(1,68 \mathrm{mg}$ de C- $\mathrm{CO}_{2}$ ) fue para el tratamiento T2, correspondiente a suelo con Vigna radiata; también se observó el crecimiento efectivo del género Rhizobium.

En cuanto a la primera y última valoración del suelo, realizadas en este estudio, en los años 2012 y 2017, respectivamente; se evidenció una ligera disminución en sus cifras. Es probable que el periodo de descanso del suelo, después de ser usado para cultivo de tabaco por veinte años y luego sin uso por siete años, ha permitido que el recurso vuelva a sus condiciones naturales, parámetros viables para la implementación de las leguminosas evaluadas.

\section{Agradecimientos}

Las autoras agradecen al personal del Laboratorio de Microbiología de la Universidad El Bosque; a la Doctora Jimena Sánchez, por su asesoría; y a todas las personas que apoyaron la realización del trabajo experimental y el documento.

\section{Referencias}

[1] M. Prager, O. Sanclemente, M. Sánchez, J. Miller y D. Ángel, "Abonos verdes: tecnología para el manejo agroecológico de los cultivos”, Agroecología, vol. 7, pp. 53-62, 2012.

[2] D. Jaramillo, Introducción a la ciencia del suelo, Medellín: Universidad Nacional de Colombia, 2002.

[3] C. E. Bogado-Ferioli, Calidad del suelo en diferentes sistemas de manejo utilizando algunos indicadores biológicos, Tesis de maestría, Departamento de Ciencia del Suelo y Ordenamiento Territorial, Universidad Nacional de Asunción, San Lorenzo, Paraguay, 2013.

[4] G. Guzmán y A. Alonso, Uso de abonos verdes (buenas prácticas en producción ecológica), Granada: Medio Ambiente y Medio Rural y Marino, 2008.

[5] M. Paredes, Fijación biológica de nitrógeno en leguminosas y gramíneas, Tesis de grado, Facultad de Ciencias 
Agrarias, Universidad Católica Argentina, Buenos Aires, Argentina, 2013.

[6] S. Calvo-García, Bacterias simbióticas fijadoras de nitrógeno, Salamanca: Universidad de Salamanca, 2011.

[7] M. García, D. Ponce de León, Y. Acosta y L. Martínez, "Influencia de la Canavalia ensiformis (L). D. C. en la actividad biológica y distribución de los agregados del suelo en un área dedicada al cultivo del tabaco", Revista Ciencias Técnicas Agropecuarias, vol. 24, n. ${ }^{\circ}$, pp. 59-64, 2015.

[8] C. Sánchez, M. Ramírez, R. Benjamín, R. Garcés, V. Montiel y G. Corredor, "Abonos verdes, alternativa para mejorar la capacidad productiva de los suelos arroceros de la Mojana”, Mosquera (Cundinamarca): Corporación Colombiana de investigación agropecuaria, 1998.

[9] D. Ángel S. y M. Prager M., "Evaluación de abonos verdes en el sistema de producción maíz-leguminosas", Acta Agronomica, vol. 39, n. ${ }^{\circ}$ 1-2, pp. 97-110, 1989.

[10] J. Marmolejo, C. Ruiz y N. Castellar, "Observaciones preliminares del comportamiento agronómico de Canavalia ensiformis (L) en condiciones del Valle del Cauca”, Acta agronómica, vol. 36, n. ${ }^{\circ}$ 1, pp. 52-62, 1986.

[11] E. M. Bucardo y M. l. Mejía, Evaluación de diferentes fechas de incorporación del frijol mungo (Vigna radiata) en asocio con maíz (Zea Mays L), Tesis de grado, Facultad de Recursos Naturales y del Ambiente, Universidad Nacional Agraria, Managua, Nicaragua, 1999.

[12] S. J. Benavides y M. V. Centeno, Efecto del agrosistema sobre el rendimiento de los cultivos y las propiedades químicas del suelo, en la comunidad Pacora, San Francisco Libre, Managua, Nicaragua, 2003, Tesis de grado, Departamento de Ingeniería Agronómica, Universidad Nacional Agraria, Managua, Nicaragua, 2006.

[13] H. A. Gómez-Sandoval, Mapa de riesgo de la calidad del agua para consumo humano de la quebrada El Raizal, en el Bata, sector Piedra de Sal en la vereda de Santa Ana. Fuente abastecedora del casco urbano del Municipio de El Espino -Boyacá, El Espino (Boyacá): Dirección de Salud Pública, 2013.

[14] Instituto Colombiano de Normas Técnicas -Icontec, "NTC 3656. Gestión ambiental. Suelo. Toma de muestras de suelo para determinar contaminación", 2004.

[15] I. D. Gómez-Guzmán, Estudio general de suelos y zonificación de tierras del departamento de Boyacá, Tomo I, Bogotá: Igac, 2005.

[16] A. Romero y R. Prato, Tabaco, ambiente y salud. La situación en Venezuela y el mundo, Caracas: Bioma, 1993.
[17] J. Celis, M. Sandoval y E. Zagal, “Actividad respiratoria de microorganismos en el suelo patagónico enmendado con lodos salmonícolas", Archivos de Medicina Veterinaria, vol. 41, n. ${ }^{\circ}$ 3, pp. 275-279, 2009.

[18] J. M. Gisbert, S. Ibáñez y H. Moreno, "La textura de un suelo", Tesis de grado, Departamento de Producción Vegetal, Universidad Politécnica de Valencia, Valencia, España, 2010.

[19] B. Cuadrado, G. Rubio y W. Santo, "Caracterización de cepas de Rhizobium y Bradyrhizobium (con habilidad de nodulación) seleccionados de los cultivos de fríjol caupi (Vigna unguiculata) como potenciales bioinóculos”, Revista Colombiana de Ciencia Química Farmacéutica, vol. 38, n. ${ }^{\circ}$ 1, pp. 78-104, 2009.

[20] P. L. Guerrero, R. Quintero, V. Espinoza, G. S. Benedicto y M. J. Sánchez, "Respiración de $\mathrm{CO}_{2}$ como indicador de la actividad microbiana en abonos orgánicos de Lupinus", Terra Latinoamericana, vol. 30, n. ${ }^{\circ} 4$, pp. 335-362, 2012.

[21] G. Stotzky, "Microbial respiration”, en Methods in soil analisys, C. Black, Ed. Madison: Assa, 1965, pp. 15501570.

[22] H. A. Valencia-Zapata, Manual de prácticas de microbiología básica, Bogotá: Universidad Nacional de Colombia, 2004.

[23] P. Vinuesca, Tema 8. Correlación: teoría y práctica, México: Universidad Nacional Autónoma de México, 2016.

[24] E. Villanueva y A. Quintana, "Aislamiento y selección de bacterias nativas de rizobios fijadores de nitrógeno, a partir de nódulos radiculares de Phaseolus vulgaris", Revista Científica de la Facultad de Ciencias Biológicas, vol. 32, n. ${ }^{\circ}$ 1, pp. 24-103, 2012.

[25] N. W. Osorio, " $\mathrm{pH}$ del suelo y disponibilidad de nutrientes", Manejo Integral del Suelo y Nutrición Vegetal, vol. 1, n. ${ }^{\circ}$ 4, pp. 1-4, 2012.

[26] A. pellegrini, “Textura y color del suelo", Curso de Edafología. Facultad de ciencias agraria y forestales UNLP, pp. 1-20.

[27] J. D. Alzate y D. Campiño, "Actividad microbiana de suelos con manejo orgánico y convencional", Trabajo de grado, Tecnología en Química, Universidad Tecnológica de Pereira, Pereira, 2014.

[28] D. P. Oliva, "Determinación de la acidez intercambiable $\left(\mathrm{Al}^{+3}+\mathrm{H}^{+}\right)$a partir del $\mathrm{pH}$ para la estimación de la capacidad de intercambio catiónico en suelos de la cuenca del pacífico en El Salvador, Honduras y Nicaragua”, Tesis de grado, Departamento de Ingeniería Agronómica, Universidad de Zamorano, Honduras, 2009. 
[29] M. P. Aramburu y R. Escribano (Eds.), Guía para la elaboración de estudios del medio físico, Madrid: Fundación Conde del Valle de Salazar, 2014.

[30] G. Cartes-Sánchez, "Degradación de suelos agrícolas y el SIRSD-s", Santiago: Oficina de Estudios y Políticas Agrarias -Odepa, 2013.

[31] G. A. Múnera y D. C. Meza, El fósforo elemento indispensable para la vida vegetal, Pereira: Universidad Tecnológica de Pereira, 2014.

[32] G. M. Martín y R. Rivera, "Mineralización del nitrógeno de la Canavalia ensiformis en un suelo ferralítico rojo de la Habana”, Cultivos tropicales, vol. 25, n. ${ }^{\circ}$, pp. 83-88, 2004.

[33] K. Müller, R. J. Seminoti, L. Antonio, S. L. Oliveira, R. Zanella y J. P. Refatti, "Biodegradação dos herbicidas imazetapir e imazapique em solo rizosférico de seis espécies vegetais", Ciência Rural, vol. 43, n. ${ }^{\circ} 10$, pp. 1790 1796, 2013.

[34] A. Burges y F. Raw, Biología del suelo, Londres: Academic Press, 1971.

[35] J. Gallardo, M. I. González y C. Pérez, La materia orgánica del suelo. su importancia en suelos naturales y cultivados, Salamanca: Ioato - Centro de Edafología y Biología Aplicada Excma. Diputación provincial, 1982.

[36] I. Yoshioka y A. Rojas, "Estimación de la actividad microbiana $\left(\mathrm{CO}_{2}\right)$ en el suelo sembrado con rábano e incorporación de cadmio, calcio y materia orgánica estabilizada", Suelos Ecuatoriales, vol. 35, n. 2 2, pp. 5355, 2005.
[37] B. D. Borja, Adaptabilidad de la leguminosa Canavalia ensiformis en comparación con Pueraria phaseoloides en la zona de limoncito, para mejorar las características fisicoquímicas del suelo, Tesis de grado, Departamento de Biología, Universidad de Guayaquil, Ecuador, 2015.

[38] J. S. García Carreón y M. R. Martínez, Abonos verdes. México: Sagarpa. Subsecretaría de Desarrollo Rural. Dirección General de Apoyos para el Desarrollo Rural, sin fecha.

[39] R. Pommeresche y S. Hansen, "Examinando la actividad de los nódulos en raíces de leguminosas”, Frick (Suiza): Research Institute of Organic Agriculture, 2017.

[40] L. M. Moreno-Conn, Caracterización de las cepas ICA L9 e ICA J96, de bacterias simbióticas fijadoras de nitrógeno y pruebas de estabilidad de inoculantes elaborados para cultivos de arveja y soya, Tesis de maestría, Departamento de Ciencias Biológicas, Universidad Javeriana, Bogotá, 2010.

[41] M. de Fernández, N. de María y M. de Felipe, "Fijación biológica de nitrógeno: factores limitantes”, Ciencia $y$ medio ambiente, pp. 195-202, 2002.

[42] R. Téllez-Molina, Abonos verdes, Hojas Divulgadoras. Madrid: Ministerio de Agricultura de España, 1949.

[43] S. Benavides y C. Marvin, Efecto del agro sistema sobre el rendimiento de los cultivos y las propiedades químicas del suelo, en la comunidad Pacora, San francisco libre, Managua, Nicaragua, Tesis de grado, Departamento de Producción Vegetal, Universidad Nacional Agraria, Managua, Nicaragua, 2006. 